\title{
Decreased heart rate variability in survivors of sudden cardiac death not associated with coronary artery disease
}

Lü Fei, Mark H Anderson, Demosthenes Katritsis, James Sneddon, Deborah J Statters, Marek Malik, A John Camm

\begin{abstract}
Background-Although heart rate variability has already been studied in survivors of sudden cardiac death secondary to coronary artery disease, an assessment of heart rate variability in survivors of sudden cardiac death not associated with coronary artery disease has not been made.

Methods-10 patients with aborted sudden cardiac death not associated with coronary artery disease (seven patients with primary ventricular fibrillation and three with unclassified mild cardiomyopathy) underwent two channel 24 hour Holter monitoring in a drug free state. All subjects were in sinus rhythm and had normal atrioventricular conduction and normal cardiac function. Spectral heart rate variability was analysed on a Holter analysis system and was expressed as total $(0.01-1.00 \mathrm{~Hz})$, low $(0.04-0.15 \mathrm{~Hz})$ and high $(0.15-0.40 \mathrm{~Hz})$ frequency components for each hour. Heart rate variability index was calculated for the 24 hour periods. 10 age and sex matched healthy subjects were taken as a control group.
\end{abstract}

Results-The spectral heart rate variability over 24 hours was significantly lower in survivors of sudden cardiac death than in controls (total 38(15) $v$ 48(14) ms; low, 25(11) $v$ 32(13) ms; and high, 13(8) $v$ 18(8) ms; $p<0.05$ for all comparisons). The differences in the ratio of low/high $(2 \cdot 19(0 \cdot 76) v 1 \cdot 98(0 \cdot 50)$, $p=0.132)$, mean heart rate $(77(12) v$ 69(12) beats $/ \mathrm{min}, p=0.070)$, and heart rate variability index (38(12) $v$ 44(16), p $=0.287$ ) over 24 hours between survivors of sudden cardiac death and controls did not reach significance. Comparisons of the hourly heart rate variability over the 24 hour period between the two groups showed that the differences in all components of heart rate variability, low/high ratio and mean heart rate were highly significant. Furthermore, there was no significant difference in the maximum hourly heart rate variability over the 24 hour period. The minimum hourly heart rate variability was, however, significantly lower in survivors of sudden cardiac death than in controls (total, 20(8) $v$
28(4) ms; low, 12(6) $v$ 17(3) ms; high, 6(2) $v 8(2) \mathrm{ms} ; \mathrm{p}<0.05$ for all comparisons).

Conclusions-These findings suggest that there is abnormal autonomic influence on the heart in patients without coronary artery disease at risk of sudden cardiac death. Hourly analysis of heart rate variability throughout the 24 hour period may provide additional information important in the identification of high risk patients.

(Br Heart F 1994;71:16-21)

Although substantial evidence shows that autonomic interventions make a large contribution to the pathophysiology of malignant ventricular tachyarrhythmias and sudden cardiac death, ${ }^{1-3}$ there are few data implicating impaired autonomic influences on the heart during normal daily activity in patients at risk of sudden cardiac death. Recently analysis of heart rate variability has provided a noninvasive measure of autonomic effects on the heart during normal daily activity. Heart rate variability has been shown to be decreased in many clinical settings. ${ }^{4-8}$ It has been reported that analysis of heart rate variability can identify patients at risk of sudden cardiac death after myocardial infarction independently of information provided by other risk factors, including clinical assessment, other ambulatory electrocardiographic variables, signal averaged electrocardiography, and left ventricular ejection fraction. ${ }^{90-13}$ Heart rate variability has been studied in survivors of sudden cardiac death secondary to coronary artery disease. Little is known, however, about heart rate variability in survivors of sudden cardiac death not associated with coronary artery disease, particularly in patients with primary ventricular fibrillation. Most previous reports are based on the heart rate variability data derived from long-term (24 hour) ambulatory electrocardiograms. Hourly heart rate variability, however, may provide more information about autonomic activity of the heart as the 24 hour values may not show profound changes in heart rate variability occurring for short periods of time. In this study, heart rate variability was therefore analysed hourly in survivors of sudden 
cardiac death not associated with coronary artery disease to obtain evidence of impaired autonomic activity on the heart and to define the role of hourly heart rate variability in the identification of patients at risk of sudden cardiac death.

\section{Patients and methods \\ PATIENTS}

Ten patients (seven men and three women), aged 45 (SD 16) (range 17 to 65 years), were consecutively enrolled from those who had experienced aborted sudden cardiac death. All the patients underwent full evaluations and were treated with implantable cardioverter defibrillators. Table 1 shows the clinical characteristics of the patients. Of the 10 patients in this study, seven had clinically normal hearts and another three had unclassified mild cardiomyopathy. None had coronary artery disease or abnormal left ventricular function. Patients with sinus node dysfunction, atrial fibrillation, abnormal atrioventricular conduction, decreased left ventricular ejection fraction, and those who needed back up pacing were excluded. Patients who were on antiarrhythmic agents or drugs affecting autonomic tone and sinus node function were also excluded. Ten age and sex matched healthy subjects were taken as controls. None of the controls had a history of heart disease and their 12 lead electrocardiograms and 24 hour Holter electrocardiograms were normal. During the recording, all patients and controls carried out their routine daily activities and nocturnal sleep.

ANALYSIS OF HEART RATE VARIABILITY

All subjects underwent two channel (modified V5 and V1 leads) 24 hour ambulatory Holter monitoring. Heart rate variability was analysed from these electrocardiograms on a Holter analysis system (Marquette Series 8000). After classification of QRS morphology, the longest and the shortest RR intervals on the $R R$ interval histogram were manually confirmed until no QRS complex was mislabelled as either an artifact or an extrasystole. The largest and the smallest $R R$ ratios on the $R R$ ratio histogram were also

Table 1 The clinical characteristics of survivors of sudden cardiac death

\begin{tabular}{lllll}
\hline Patient No & Age Sex & Aetiology & $\begin{array}{l}\text { Inducibility of } \\
\text { VT or VF }\end{array}$ & Late potentials \\
\hline 1 & $41 \mathrm{M}$ & Unknown & - & $\mathrm{N}$ \\
2 & $61 \mathrm{~F}$ & Cardiomyopathy & - & $\mathrm{A}$ \\
3 & $53 \mathrm{M}$ & Cardiomyopathy & + & $\mathrm{A}$ \\
4 & $51 \mathrm{M}$ & Unknown & - & $\mathrm{N}$ \\
5 & $33 \mathrm{M}$ & Cardiomyopathy & + & $\mathrm{N}$ \\
6 & $39 \mathrm{~F}$ & Unknown & - & $\mathrm{N}$ \\
7 & $17 \mathrm{M}$ & Unknown & - & $\mathrm{N}$ \\
8 & $29 \mathrm{M}$ & Unknown & - & $\mathrm{N}$ \\
9 & $64 \mathrm{~F}$ & Unknown & - & $\mathrm{N}$ \\
10 & $65 \mathrm{M}$ & Unknown & - &
\end{tabular}

The patients with unknown aetiology were these without any overt structural heart disease (including normal cardiac biopsy). The patients with cardiomyopathy were heterogeneous with the diagnosis being made primarily on abnormal right ventricular biopsies without other pathological findings. Patient 5 showed a mild hypokinesia of the right ventricle on angiography and had a normal cardiac biopsy. Patient 7 had normal clinical investigations except abnormal late potentials. As it is inappropriate to classify him as having a defined visually checked to ensure all normal and abnormal QRS complexes on the ambulatory electrocardiograms were correctly labelled. When calculating values of heart rate variability, only normal to normal intervals were included. Each interval that was to be excluded due to extrasystoles or artifacts was replaced by holding the previous coupling interval level throughout the excluded interval to the next valid coupling interval. The beat to beat fluctuations were transformed to frequency with the fast Fourier transformation and the spectral measures were computed as the square root of areas under the power spectrum. In this study, spectral heart rate variability was expressed as total $(0.01-1.00$ $\mathrm{Hz})$, low $(0.04-0.15 \mathrm{~Hz})$ and high $(0 \cdot 15-$ $0.40 \mathrm{~Hz}$ ) frequency components for each hour. Mean heart rate was also calculated from the 24 hour Holter recordings.

The QRS files were transferred to a personal computer for computation of heart rate variability index. ${ }^{14}$ The main peak of the distribution diagram of the $R R$ interval frequency was approximated to a triangle. The height of the triangle is equal to the frequency of observation of the most common RR interval (the modal frequency) and the area of the triangle is approximately equal to the total number of $R R$ intervals. The heart rate variability index was calculated from the length of the base of this triangle according to simple geometrical rules: heart rate variability index = total number of $R R$ intervals / modal $R R$ interval frequency.

STATISTICAL ANALYSIS

All data were expressed as mean (SD) except in figure 1 (SE). Student's $t$ test was used to compare differences between groups. A p value $<0.05$ was considered significant

\section{Results}

Table 1 shows the clinical characteristics of the patients. Seven of the 10 patients had a clinically normal heart despite extensive investigations and could therefore be considered to have had primary ventricular fibrillation. The remaining three patients had unclassified mild cardiomyopathy, two had right ventricular myocardial fibrosis, and the other had a hypokinetic right ventricle on angiography with a normal right ventricular myocardial biopsy. None of these 10 patients had coronary artery disease or impaired left ventricular ejection fraction. During electrophysiological study, ventricular tachycardia or fibrillation was inducible in only two patients. Most of the patients had occasional ventricular extrasystoles during the 24 hour period (range from 1 to 4315). The difference in total number of ventricular extrasystoles during the 24 hour recordings between controls (45(94) beats/24 hours) and survivors of sudden cardiac death (1033(1487) beats / 24 hours) was significant after normalisation by logarithmic transformation $(0.77(0.86)$ v $2 \cdot 06(0.39) \log$ units, $\mathrm{p}<0.05)$. Over 24 hours the spectral heart rate variability was 
Table 224 hour heart rate variability ( $H R V$ ) in survivors of sudden cardiac death and controls

\begin{tabular}{|c|c|c|c|c|c|c|}
\hline Patient No & $H R V$ Index & Total (ms) & $\operatorname{Low}(m s)$ & High (ms) & Low/high & Mean HR (beats/min) \\
\hline \multicolumn{7}{|l|}{ Survivors: } \\
\hline $\begin{array}{r}1 \\
2 \\
3 \\
4 \\
5 \\
6 \\
7 \\
8 \\
9 \\
10\end{array}$ & $\begin{array}{l}25 \\
47 \\
23 \\
38 \\
43 \\
50 \\
57 \\
46 \\
31 \\
25\end{array}$ & $\begin{array}{l}26 \\
22 \\
30 \\
28 \\
54 \\
59 \\
57 \\
48 \\
25 \\
30\end{array}$ & $\begin{array}{l}19 \\
13 \\
19 \\
18 \\
39 \\
40 \\
34 \\
35 \\
17 \\
16\end{array}$ & $\begin{array}{r}7 \\
6 \\
9 \\
10 \\
13 \\
24 \\
31 \\
14 \\
6 \\
10\end{array}$ & $\begin{array}{l}2 \cdot 71 \\
2 \cdot 17 \\
2 \cdot 11 \\
1.80 \\
3.00 \\
1 \cdot 67 \\
1 \cdot 10 \\
2.50 \\
2 \cdot 80 \\
1 \cdot 60\end{array}$ & $\begin{array}{l}84 \\
76 \\
80 \\
80 \\
75 \\
69 \\
77 \\
76 \\
83 \\
65\end{array}$ \\
\hline Mean (SD) & $38(12)$ & $38(15)$ & $25(11)$ & $13(8)$ & $2 \cdot 15(0.61)$ & $76(6)$ \\
\hline $\begin{array}{c}\text { Controls: } \\
1 \\
2 \\
3 \\
4 \\
5 \\
6 \\
7 \\
8 \\
9 \\
10 \\
\text { Mean (SD) }\end{array}$ & $\begin{array}{l}34 \\
51 \\
53 \\
27 \\
69 \\
62 \\
47 \\
29 \\
22 \\
47 \\
44(16)\end{array}$ & $\begin{array}{l}37 \\
33 \\
42 \\
42 \\
84 \\
52 \\
53 \\
54 \\
42 \\
39 \\
48(14)^{\star}\end{array}$ & $\begin{array}{l}26 \\
17 \\
27 \\
27 \\
64 \\
31 \\
33 \\
39 \\
27 \\
24 \\
32(13)^{\star}\end{array}$ & $\begin{array}{l}13 \\
10 \\
11 \\
12 \\
34 \\
25 \\
27 \\
19 \\
15 \\
13 \\
18(8)^{\star}\end{array}$ & $\begin{array}{l}2.00 \\
1 \cdot 70 \\
2.45 \\
2.25 \\
1.88 \\
1.24 \\
1.27 \\
2.05 \\
1.80 \\
1.85 \\
1.85(0.38)\end{array}$ & $\begin{array}{l}80 \\
53 \\
67 \\
68 \\
56 \\
71 \\
87 \\
73 \\
67 \\
71 \\
69(10)\end{array}$ \\
\hline
\end{tabular}

${ }^{\star} \mathrm{p}<0.05$ (paired $t$ test).

significantly lower in survivors of sudden cardiac death than in normal controls, but the difference in the averaged values of low to high ratio, heart rate variability index, and mean heart rate did not reach significance (table 2). There was also no significant difference in the 24 hour heart rate variability between patients with normal (six patients) and abnormal (four patients) late potentials, and between patients with cardiomyopathy and those with clinically normal hearts (table 3).

Figure 1 shows the pooled hourly heart rate variability and mean heart rate over the 24 hour period from each group. The figure shows clearly that there was a significant decrease in heart rate variability and a significant increase in mean heart rate in survivors

Table 3 Mean (SD) heart rate variability in survivors of sudden cardiac death in relation to ventricular late potentials and aetiology

\begin{tabular}{llllll}
\hline & \multicolumn{2}{l}{ Late potentials } & & \multicolumn{2}{l}{ Aetiology } \\
\cline { 2 - 3 } & Normal & Abnormal & & Cardiomyopathy & Primary VF \\
\hline No & 6 & 4 & 3 & 7 \\
Total (ms) & $36(14)$ & $41(17)$ & & $35(17)$ & $39(15)$ \\
Low (ms) & $24(10)$ & $26(12)$ & & $24(14)$ & $26(10)$ \\
High (ms) & $12(6)$ & $15(11)$ & & $9(4)$ & $14(9)$ \\
Low/high ratio & $2 \cdot 18(0.56)$ & $2 \cdot 09(0 \cdot 78)$ & & $2 \cdot 42(0 \cdot 50)$ & $2 \cdot 03(0.66)$ \\
Mean heart rate & $76(8)$ & $77(2)$ & & $77(3)$ & $76(7)$ \\
$\quad$ (beats/min) & & & & &
\end{tabular}

Late potentials were considered as abnormal if any two of the three variables (total duration of $\mathrm{QRS}$ complex, root mean square voltage of the last $40 \mathrm{~ms}$ of $\mathrm{QRS}$ complex, and the duration of low amplitude signals under $40 \mathrm{mV}$ ) exceed their normal limits. All comparisons were NS

Table 4 Maximum and minimum hourly heart rate variability in controls and survivors of sudden cardiac death

\begin{tabular}{llllllll}
\hline & Controls & \multicolumn{3}{l}{ Survivors } \\
\cline { 2 - 3 } & Total & Low & High & & Total & Low & High \\
\hline Minimum (ms) & $28(4)$ & $17(3)$ & $8(2)$ & & $20(8)^{\star}$ & $12(6)^{\star}$ & $6(2)^{\star}$ \\
Maximum (ms) & $75(26)$ & $47(18)$ & $35(20)$ & & $66(17)$ & $45(14)$ & $27(17)$ \\
SD (ms) & $13(6)$ & $8(4)$ & $9(5)$ & & $11(3)$ & $8(3)$ & $6(4)$ \\
Range (ms) & $46(24)$ & $30(17)$ & $27(19)$ & & $46(14)$ & $33(11)$ & $21(16)$ \\
\hline
\end{tabular}

${ }^{\star} \mathrm{p}<0.05$. Range is the difference between the maximum and minimum hourly heart rate variability over the 24 hour period; SD is the standard deviation of the hourly heart rate variability for 24 hours; values are mean (SD). of sudden cardiac death. This difference, however, was not evident from the data averaged from 24 hour recordings. We therefore compared the hourly heart rate variability over a 24 hour period. As expected, the differences in all frequency components of heart rate variability (total, 40 (5) $v 49$ (4) $\mathrm{ms}$, $\mathrm{p}<0.001$; low, 27 (3) $v 31$ (3) $\mathrm{ms}$, $\mathrm{p}<0.001$; high, 14 (3) $v 18$ (4) $\mathrm{ms}, \mathrm{p}<$ $0.001)$, low to high ratio $(1.90(0.27) v 1.74$ $(0.26), p=0.004)$ and mean heart rate $(78$ (8) $v 70$ (5) beats $/ \mathrm{min} \mathrm{p}<0.001$ ) between survivors of sudden cardiac death and controls were highly significant.

To gain an insight into the mechanism underlying the abnormal heart rate variability in survivors of sudden cardiac death, we compared the difference between the maximum and minimum hourly heart rate variability throughout the 24 hour period. There were 229 hours of valid data for controls and 213 hours for survivors of sudden cardiac death after exclusion of noisy segments of Holter electrocardiographic recordings. There was no significant difference in the maximum hourly heart rate variability between controls and survivors of sudden cardiac death (total, 75 (26) v 66 (17) ms; low, 47 (18) v 45 (14); high, $35(20) v 27$ (17) $\mathrm{ms}, \mathrm{p}>0.05$ for all comparisons). The minimum hourly heart rate variability, however, was significantly lower in survivors of sudden cardiac death than in controls (fig 2). There was also no significant difference in the SD and range (the difference between the maximum and minimum) of the hourly heart rate variability between the groups (table 4).

\section{Discussion}

Recently it has been reported that heart rate variability provides important data for identifying patients at risk of sudden cardiac death after myocardial infarction. ${ }^{15}$ Little is known, however, about heart rate variability 
Figure 1 (A) Total, (B) low, and $(C)$ high

frequency components of hourly heart rate variability and (D) hourly mean heart rate (HR) over the 24 hour period in controls and survivors of sudden cardiac death. The data are presented as mean (SE).
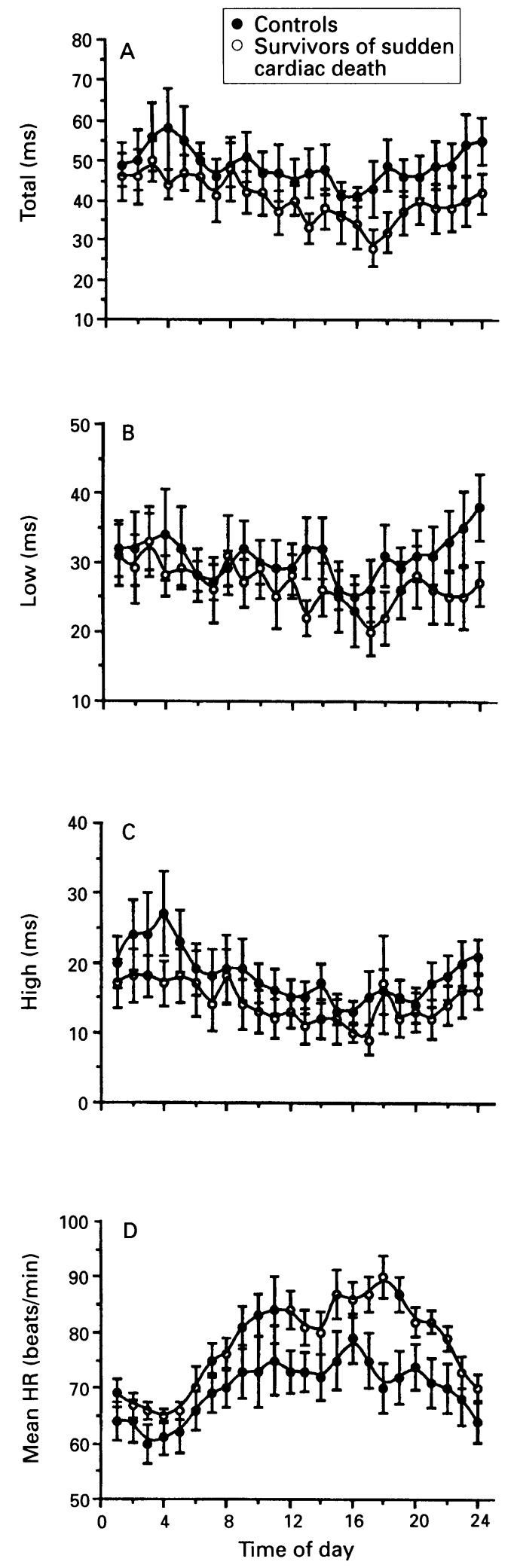

in survivors of sudden cardiac death not associated with coronary artery disease. Our results show that the overall heart rate variability over 24 hours is significantly decreased in these patients and this is consistent with previous reports on heart rate variability in survivors of out of hospital cardiac arrest. ${ }^{16-18}$ Preliminary observations of heart rate variability in patients experiencing sudden cardiac death not associated with acute myocardial infarction was reported by Martin and colleagues. ${ }^{16}$ They found that heart rate variability was significantly decreased in three patients who died suddenly during ambulatory electrocardiographic monitoring. Huikuri et al recently reported that the high frequency component of heart rate variability was significantly decreased in 22 survivors of sudden cardiac death without detecting any significant differences in the amplitude of circadian rhythm of heart rate, but statistical significance was not reached in the low frequency component $\left(14\right.$ (13) $v 22$ (12) $\mathrm{ms}^{2} \times 10$, NS). ${ }^{19}$ The study of Dougherty and Burr showed that the low frequency component of heart rate variability was significantly lower in 16 survivors of sudden cardiac death than in controls, whereas the difference in the high frequency power $(2.5(1.6) v 3.4(1.2) \log$ units, $p=0.13$ ) was not significant. ${ }^{20}$ It is worth noting that the patients in our study did not have coronary artery disease and most of them had had primary ventricular fibrillation. None of our patients had decreased left ventricular ejection fraction or was on antiarrhythmic drugs. This is different from previous studies, in which most patients had had a myocardial infarction, many had decreased cardiac function, and some were on antiarrhythmic drugs. Heart rate variability has been shown to be decreased in patients with congestive heart failure, ${ }^{48}$ and antiarrhythmic drugs may impair evaluation of cardiac autonomic tone with analysis of heart rate variability by modifying sinus node function or by influencing autonomic activity directly. ${ }^{21}$ The small number of patients that we have been able to study may explain the failure to find a significant difference in the averaged values of low to high ratio, mean heart rate, and heart rate variability index from the 24 hour period in this study. By hourly analysis of heart rate variability in this group of patients, however, the differences in heart rate variability, low to high ratio, and mean heart rate between survivors of sudden cardiac death and controls were shown to be highly significant. As all of these patients had experienced cardiac arrest, circulatory standstill during the period of cardiac arrest may have caused myocardial injury and may have affected autonomic function (heart rate variability). It seems unlikely, however, that this injury was extensive as we were unable to perceive any remaining evidence of significant structural or functional injury to the myocardium at the time of this study although a contribution of the cardiac arrest to the observed abnormalities in heart rate variability cannot be completely precluded. A larger prospective study on heart rate variability will be required to fully define the significance of analysis of heart rate variability for risk stratification in patients without coronary artery disease.

Spectral analysis of heart rate variability can partly separate parasympathetic from sympathetic activity on the heart. ${ }^{22-28}$ The low frequency component of spectral heart rate variability gives a measure of sympathetic activity with some influence from vagal activity. ${ }^{22}$ The high frequency component is 


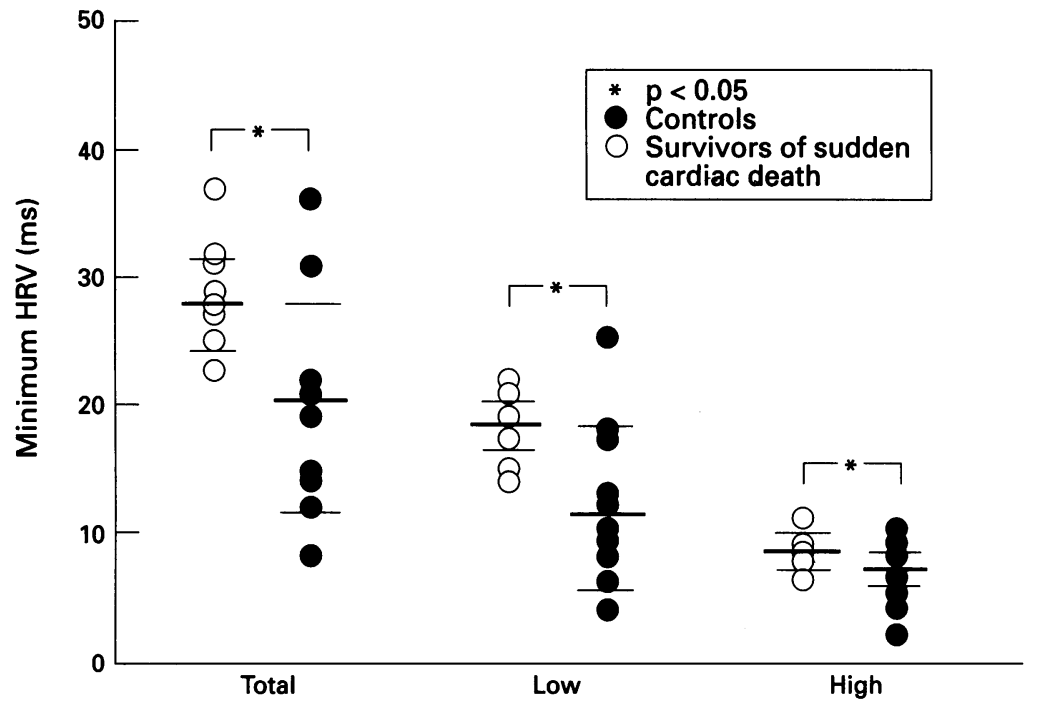

Figure 2 Minimum hourly heart rate variability (HRV) was significantly lower in survivors of sudden cardiac death than in controls for total, low, and high frequency components of the minimum hourly heart rate variability. groups. It is worth pointing out that there was a greater number of ventricular extrasystolic complexes in the patients than in the controls although most of these patients had few ventricular extrasystoles. Frequent ventricular extrasystoles may have a notable impact on the spectral heart rate variability. This influence is, however, unlikely to be important in our study as the number of ventricular extrasystoles in either group was small compared with the total number of normal sinus beats over 24 hour recordings.

In summary, heart rate variability is depressed in patients with ventricular fibrillation not associated with coronary artery disease; our findings support the hypothesis that there is abnormal autonomic influence on the heart in patients at risk of sudden cardiac death; and hourly analysis of heart rate variability may provide additional information important in the identification of patients at high risk.

almost exclusively mediated by vagal activity, ${ }^{23-25}$ and the total heart rate variability is predominantly influenced by cardiac vagal activity. ${ }^{26-28}$ Kleiger et al reported that patients with decreased heart rate variability had either decreased vagal tone or increased sympathetic tone. ${ }^{10}$ The ratio of low/high frequency components has been used as an index of sympathovagal balance. ${ }^{24} 29$ The results in this study that heart rate variability was decreased and low/high ratio was increased suggest that there may be an increased sympathetic or decreased vagal influence on the heart in survivors of sudden cardiac death. This is further supported by the increased mean heart rate in these patients. It is well known that abnormal autonomic activity plays an important part in the development of sudden cardiac death after myocardial infarction. ${ }^{1-3}$ The altered autonomic influence on the heart may also be of importance in sudden cardiac death without coronary artery disease. As mean heart rate represents the overall autonomic influence on the heart, we did not adjust for mean heart rate in this study when comparing the difference in heart rate variability although it has been shown that there is an association of heart rate variability to mean heart rate. ${ }^{26} 30$

In our study, the minimum hourly heart rate variability was significantly lower whereas the maximum hourly heart rate variability remained unchanged in survivors of sudden cardiac death compared with controls. This suggests that there is a greater reduction of heart rate variability in survivors of sudden cardiac death under some circumstances. What these circumstances are remains to be elucidated. Furthermore, it seems that there was no significant alteration in the amplitude of circadian rhythm of heart rate variability in survivors of sudden cardiac death compared with controls as the differences in the range (difference between maximum and minimum) of heart rate variability over the 24 hour period were not significant between the
1 Schwartz PJ, La Rovere MT, Vanoli E. Autonomic nervous system and sudden cardiac death. Experimental basis and clinical observations for post-myocardial infarction risk stratification. Circulation 1992;85: 77-91.

2 Malliani A, Schwartz PJ, Zanchetti A. Neural mechanisms 705-15.

3 Verrier RL. Neurogenic aspects of cardiac arrhythmias. In: El-Sherif N, Samet $\mathrm{P}$ eds: Cardiac pacing and electrophysiology. Philadelphia: W B Saunders 1991:77-91.

4 Casolo G, Balli E, Taddei T, Amuhasi J, Gori C. Decreased spontaneous heart rate variability in congestive heart failure. Am $₹$ Cardiol 1989;64:1162-7.

5 Airaksinen KEJ, Ikäheimo MJ, Linnaluoto $M$, Niemelä $M$, Takkunen JT. Impaired vagal heart rate control in coronary artery disease. $\mathrm{Br}$ Heart $\mathcal{f}$ 1987;58:592-7.

6 Northcote RJ, MacFarlane P, Kesson CM, Ballantyne D. Continuous 24-hour electrocardiography in thryrotoxicosis before and after treatment. Am Heart $\mathcal{f} 1986 ; 112$ : 339-44.

7 Sands KEF, Appel ML, Lilly LS, Schoen FJ, Mudge GH $\mathrm{Jr}$, Cohen RJ. Power spectral analysis of heart rate $\mathrm{Jr}$ variability in human cardiac transplant recipients. variability in human ca

8 Saul JP, Arai Y, Berger RD, Lilly LS, Colucci WS, Cohen RJ. Assessment of autonomic regulation in chronic congestive heart failure by heart rate spectral analysis. $\mathrm{Am} \mathcal{F}$ Cardiol 1988;61:1292-9.

9 Farrell TG, Bashir Y, Cripps T, Malik M, Poloniecki J, Bennett ED, Ward DE, Camm AJ. Risk stratification for arrhythmic events in postinfarction patients based on heart rate variability, ambulatory electrocardiographic variables and the signal-averaged electrocardiogram. f Am Coll Cardiol 1991;18:687-97.

10 Kleiger RE, Miller JP, Bigger JT Jr, Moss AJ, and the Multicenter Post-Infarction Research Group. Decreased heart rate variability and its association with increased mortality after acute myocardial infarction. Am $\mathcal{f}$ Cardiol 1987;59:256-62.

11 Cripps TR, Camm AJ. Prediction of arrhythmic events in patients following myocardial infarction. Clin Cardiol 1989;12:661-5. Hombach V. Predictive value of heart rate variability, ambulatory monitoring and late potentials in patients with sustained ventricular tachycardia during pro-
grammed ventricular stimulation [abstract]. fournal of Ambulatory Monitoring 1992;5(suppl):31.

13 Pedretti R Gementl A, Etro D, Bonelli R, Laporta A Maslowsky F, Carù B. Role of heart rate variability in patients at high risk of arrhythmic events after acute myocardial infarction. New Trends in Arrhythmias 1992; VIII:433-6.

14 Cripps TR, Malik M, Farrel TG, Camm AJ. Prognostic value of reduced heart rate variability after myocardial Br Heart f 1991;65:14-9. Kleiger RE, Rottman JN. Frequency domain measures of heart period variability and mortality after myocardial infarction. Circulation 1992;85:164-71.

16 Martin GJ, Magid NM, Myers G, Barnett PS, Schaad JW, Weiss JS, et al. Heart rate variability and sudden death secondary to coronary artery disease during ambulatory electrocardiographic monitoring. Am $\mathcal{f}$ Cardiol 1987; 60:86-9. in life-threatening arrhythmias. Am Heart $f$ 1980;100:

12 Osterhues HH, Eggeling T, Höher $M$, Weismüller $P$, infarction: clinical evaluation of a new analysis method.

15 Bigger JT Jr, Fleiss J,, Steinman RC, Rolnitzky LM, 
17 Van Hoogenhuyze D, Martin GJ, Weiss JS, Schaad J, Fintel D, Singer DH. Heart rate variability 1989. An update. F Electrocardiol 1989;22(suppl):204-8.

18 Singer DH, Martin GJ, Magid N, Weiss JS, Schaad JW, Kehoe $\mathrm{R}$, et al. Low heart rate variability and sudden cardiac death. $\mathcal{f}$ Electrocardiol 1988;21:S46-55.

19 Huikuri HV, Linnaluoto MK, Seppänen T, Airaksinen KEJ, Kessler KM, Takkunen JT, Myerburg RJ. Circadian rhythm of heart rate variability in survivors of

20 Dougherty CM, Burr RL. Comparison of heart rate variability in survivors and nonsurvivors of sudden cardiac

arrest. Am $\mathcal{F}$ Cardiol 1992;70:441-8.
21 Böcker D, Shenasa M, Borggrefe M, Fetsch T, Breithardt G. Late potentials, heart rate variability, and electrocardiography. Current Opinion in Cardiology 1993;8:39-53.

22 Shin SJ, Tapp. WN, Reisman SS, Natelson BH Assessment of autonomic regulation of heart rate variability by the method of complex demodulation. IEEE Trans Biomed Eng 1989;36:274-83.

23 Lipsitz LA, Mietus J, Moody GB, Goldberger AL Spectral characteristics of heart rate variability before and during postural tilt. Relations to aging and risk of syncope. Circulation 1990;81:1803-10.

24 Pagani M, Lombardi F, Guzzetti S, Rimoldi O, Furlan R, Pizzinelli P, et al. Power spectral analysis of heart rate and arterial pressure variabilities as a marker of sympatho-vagal interaction in man and conscious dog. Circ Res 1986;59:178-93.

25 Vybiral T, Bryg RJ, Maddens ME, Boden WE. Effect of passive tilt on sympathetic and parasympathetic components of heart rate variability in normal subjects. Am $\mathcal{f}$ Cardiol 1989;63:1117-20.

26 Huikuri HV, Kessler KM, Terracall E, Castellanos A Linnaluoto MK, Myerburg RJ. Reproducibility and circadian rhythm of heart rate variability in healthy sub jects. Am f Cardiol 1990;65:391-3.

27 Pomeranz B, Macaulay RJB, Caudill MA, Kutz I, Adam $\mathrm{D}$, Gordon $\mathrm{D}$, et al. Assessment of autonomic function in humans by heart rate spectral analysis. Am F Physio 1985;248:H151-3.

28 Akselrod S, Gordon D, Ubel FA, Shannon DC, Barger AC, Cohen RJ. Power spectral analysis of heart rat fluctuation: a quantitative probe of beat-to-beat cardiovascular control. Science 1981;213:220-2.

29 Lombardi F, Sandrone G, Pernpruner S, Sala R, Garimoldi $M$, Cerutti $S$, et al. Heart rate variability as an index of sympathovagal interaction after acute myocardial infarction. Am fCardiol 1987;60:1239-45.

30 Fleiss JL, Bigger JT Jr, Rolnitzky LM. The correlation between heart period variability and mean period between heart period variability
length. Stat Med 1992;11:125-9. 